\title{
Exposure biomarkers and risk from gluing and heating of polyurethane: a cross sectional study of respiratory symptoms
}

Margareta Littorin, Lars Rylander, Gunnar Skarping, Marianne Dalene, Hans Welinder, Ulf Strömberg, Staffan Skerfving

\begin{abstract}
Objectives-To define the relation between exposure to polyurethane (PUR) glue, biomarkers of exposure and effect, and work related symptoms that occur at least once a week.

Methods-In a cross sectional study, 152 workers and 14 clerks in a factory with exposure to sprayed and heated PUR glue containing 4,4'-diphenylmethane (MDI) or 1,6-hexamethylene (HDI) di-isocyanate were examined with gas chromatographymass spectrometry (GC-MS) for metabolites of MDI in plasma (P-MDX) and urine (U-MDX), 2,4- and 2,6-toluene diisocyanate (TDI; P-TDX, U-TDX) and $H D I$ in plasma and urine, specific serum IgG (S-IgG-MDI, S-IgG-HDI, and S-IgGTDI, respectively) and IgE (S-IgE-MDI). Work related symptoms of the eyes and airways (nose or lower airways, or both), and lung function were also evaluated.
\end{abstract}

Results-P-MDX was detected in $65 \%$ of the workers, U-TDX in $47 \%$, HDX in none. Three per cent were positive for S-IgEMDI, 33\% for S-IgG-MDI, 32\% for S-IgGTDI, and $12 \%$ for S-IgG-HDI. A few clerks had metabolites, and some had antibodies. Most metabolites and immunoglobulins were slightly correlated-for example, P-MDX $v$ S-IgG-MDI: $r_{s}=0.21$. Workers who heated glue had increased P-MDX (odds ratio $(O R)=12$ for a value above the median) and S-IgG-MDI $(O R=3.7)$, sprayers $P-2,4-T D X(O R=6.2)$ and $P-2,6-$ TDX $(O R=16)$. Twenty six per cent of the workers had work related symptoms of the airways, $21 \%$ from the nose, $11 \%$ from the lower airways. Spraying of glue increased the risk of work related symptoms and slightly decreased lung function. U-MDX was associated with work related symptoms from the airways $(\mathrm{OR}=3.7)$ and $P-2,6-T D X$ with work related symptoms from the lower airways $(\mathrm{OR}=6.6)$. S-IgG-MDI was related to work related symptoms from the airways $(\mathrm{OR}=\mathbf{2 . 6})$.

Conclusions-There were relations between exposures to sprayed and heated PUR glue based on MDI and HDI, concentrations of metabolites of MDI and TDI in plasma and urine, specific IgG serum antibodies against MDI, TDI, and HDI, and work related symptoms.

(Occup Environ Med 2000;57:396-405)

Margareta Littorin

margareta.littorin@ymed.lu.se

Accepted 26 January 2000
Workers exposed to isocyanates are at risk of contracting respiratory disorders. ${ }^{1-6}$ Exposure occurs during spraying and heating of polyurethanes (PURs). Metabolites of 4,4'diphenylmethane di-isocyanate (MDI) in plasma (P-MDX) and urine (U-MDX) have been detected after exposure to thermal degradation products of MDI-PURs. ${ }^{7-9}$ Further, in a factory handling PUR glue, the use of MDI glue was associated with such metabolites, which were, in turn, associated with MDI specific IgG antibodies and with work related symptoms. ${ }^{10}$ However, the knowledge of relations between exposure, biomarkers, and various effects is still very incomplete.

Thus, a new cross sectional survey was performed in the same factory 19 months after the first one. We particularly focused on the relevance of isocyanate metabolites and specific antibodies for assessment of exposure and risk.

\section{Material and methods}

FACTORY AND EXPOSURE

The production of parts for the car industry included the joining of soft (sheets of polyvinyl chloride (PVC), polyesters, polyethers, or leather), semisoft (flexible foam, consisting of technical grade toluene di-isocyanate (TDI), a mixture of the 2,4- and 2,6-monomers), and hard (acrylonitrile-butadiene-styrene, masonite, or fibre board) materials with isocyanate based glues. ${ }^{10}$ From the early 1990s, glues based on MDI predominated; also, glues containing hexamethylene (HDI) were introduced. Earlier, glues based on TDI had prevailed. According to information from the supplier, the spray glue used most often now consisted of $30 \%-100 \%$ polyisocyanate (free MDI <20\%), 10\%-30\% methyl ethyl ketone, $10 \%-30 \%$ ethyl acetate, and $30 \%-100 \%$ acetone. For a few products another glue was chosen containing a water dispersed PUR acryl copolymer with a hardener of polyisocyanate (free HDI <0.4\%). The spray glues were applied by a robot or by manual spraying in booths in the general workshop or in a separate gluing room, the MDI based glues were also applied by a gluing machine in that room. Heat from heat guns $\left(200^{\circ} \mathrm{C}-500^{\circ} \mathrm{C}\right)$, or from other sources-such as infrared heaters $\left(180^{\circ} \mathrm{C}\right.$ $200^{\circ} \mathrm{C}$ ) - was applied to activate the glues based on MDI. Further, melting glues were used, containing $30 \%-100 \%$ of prepolymerised MDI (free MDI $1 \%-3 \%$ ), or colophony (pine resin). These were heated up to $220^{\circ} \mathrm{C}-$ $240^{\circ} \mathrm{C}$. Certain work tasks involved use of other glues containing ethylene vinyl acetate, 
polyamide, latex-ammonia, or occasionally, cyanoacrylate. The parts were joined by moulding $\left(110^{\circ} \mathrm{C}-160^{\circ} \mathrm{C}\right)$ or by electromagnetic welding.

In 1993, air measurements showed low concentrations of di-isocyanate monomers, irrespective of whether gluing took place or not: during 40 sampling periods of 30-60 minutes, concentrations of MDI were <0.2-7.1, of HDI $<0.1-0.7$, and of TDI $<0.1 \mu \mathrm{g} / \mathrm{m}^{3} .{ }^{10}$ By use of an isologger filter tape instrument (MDAScientific, Chicago, USA), peaks of compounds containing isocyanate have been found during heating and spraying operations (G Skarping and $\mathrm{H}$ Tinnerberg, personal communication). ${ }^{11}$ Also, air concentrations of organic solvents were measured at nine work stations. During 38 sampling periods of 20-160 minutes, acetone, ethyl acetate, methyl ethyl ketone, and toluene were found in the workers' breathing zones at concentrations of $7-410,3-120,3-110$, and $<0.1-1.5 \mathrm{mg} / \mathrm{m}^{3}$, respectively; the highest concentrations were found in the gluing room.

In late 1993, the company took measures to reduce the exposure to isocyanates and solvents, by trying to enforce rules on use of personal protective equipment (respirators, mostly half piece ones, and rubber gloves) when spraying glue, but not when heating it.

SUBJECTS

Ninety eight per cent of active employees (121 women and 31 men) and 14 clerks participated (table 1). When accounting for employment time, long term ( $>1$ month) absences have been subtracted. Twenty seven workers were

Table 1 Descriptive characteristics of 166 current employees potentially exposed to sprayed or heated polyurethane (PUR) glue

\begin{tabular}{|c|c|c|c|c|}
\hline & \multicolumn{3}{|l|}{ Workers * } & \multirow{3}{*}{$\begin{array}{l}\text { Clerks } \\
n\end{array}$} \\
\hline & \multirow[b]{2}{*}{$n$} & \multicolumn{2}{|c|}{ Glue exposure } & \\
\hline & & Sprayed & Heated & \\
\hline All & 152 & & & 14 \\
\hline Glue & 81 & & & 0 \\
\hline Heat & 77 & & & \\
\hline Gun & 49 & & & \\
\hline Glue spraying & 26 & Yes & Yes & \\
\hline Preapplied glue & 23 & No & Yes & \\
\hline Other heat $†$ & 28 & & & \\
\hline Glue spraying & 19 & Yes & Yes & \\
\hline Melting glue $\ddagger$ & 9 & No & Yes & \\
\hline \multicolumn{5}{|l|}{ No heat $₫$} \\
\hline Glue spraying $\llbracket$ & 4 & Yes & No & \\
\hline No glue & 71 & No & No & 14 \\
\hline Women/men & $121 / 31$ & & & $9 / 5$ \\
\hline Age (y; median, range) & $\begin{array}{l}42 \\
(20-64)\end{array}$ & & & $48(33-62)$ \\
\hline Women & $\begin{array}{c}44 \\
(23-64)\end{array}$ & & & \\
\hline Men & $\begin{array}{c}34 \\
(20-61)\end{array}$ & & & \\
\hline Employment time (months; median, range) & $\begin{array}{c}94 \\
(4-529)\end{array}$ & & & $184(38-440)$ \\
\hline Smokers/ex-smokers/non-smokers & $51 / 25 / 76$ & & & $1 / 6 / 7$ \\
\hline \multicolumn{5}{|l|}{ Atopy } \\
\hline History (positive/uncertain/negative) & $22 / 20 / 110$ & & & $6 / 2 / 6$ \\
\hline Phadiatop ${ }^{\circledR}$ test (positive) & $35^{\star \star}$ & & & 4 \\
\hline Serum IgE $(>100 \mathrm{kU} / \mathrm{l})$ & $19^{\star \star}$ & & & 2 \\
\hline
\end{tabular}

*Not included in table: three present workers who declined to participate.

tOne worker changed job tasks from gun to other heat during the preceding 3 months.

$\ddagger$ All workers applying melting glue used MDI based glues, some also used colophony based glues. §Four workers changed job tasks from heat to no heat during the preceding 3 months.

TThe gluers in this group both sprayed glue and served a glueing machine; two workers were transferred from heat 1 month ago; a third worker helped at heating jobs during afternoon shifts. ${ }^{\star \star}$ Three values missing. on long term sick leave at the time of the present investigation. They were also examined, but have not been included in the present study base (see discussion).

Exposure information, including use of protective equipment, was obtained from each employee by a questionnaire with supplementary interview. Within groups of two to eight workers, the personnel often rotated between the work tasks. The workers have been classified into groups, according to their main work tasks, especially regarding gluing and heating of isocyanate based glues during the past month (for most subjects this was the same as at least the past 3 months, table 1). All isocyanate gluers used MDI based glues, some also used glues based on HDI. Four female gluers used the gluing machine or spray glued in the separate gluing room. Workers not occupied with gluing or heating PURs had intermittent exposure to isocyanates with tasks such as serving the MDI gluing robot with material, cutting, sewing, or performing electromagnetic welding of textiles, coated with flexible PUR foam or glued with non-isocyanate glues. ${ }^{12}$ They were all classified as not (directly) exposed to sprayed or heated PUR glue. Cleaners, repair men-for example, those removing PUR from utensils by the use of acetone or acetylene gas - and storemen-for example, those sawing masonite or fibre board-were also assigned to the no glue no heat group. Only three men had jobs categorised as exposed to glue or heat. Some clerks had their office rooms in the immediate proximity of the production area.

\section{HEALTH EXAMINATIONS}

Medical and occupational histories were obtained from self administered questionnaires, modified after Nielsen et $a l,{ }^{13}$ and were supplemented with interviews by a physician.

In the questionnaire, smoking habits were registered as smoker, never smoker, and ex-smoker ( $>6$ months since stopping smoking). Atopy was considered to be present if the subject reported atopic dermatitis, urticaria (if a probable cause could be established), allergic rhinitis (hay fever), or asthma during childhood or adolescence.

Symptoms from the eyes (at least one of: itching, running, burning), nose (at least one of running, stuffiness, sneezing), or lower airways (at least one of severe dry cough, dyspnoea, wheezing, chest tightness) presently or earlier in adult life were registered. Work related symptoms of the eyes, nose, lower airways, and airways (nose, or lower airways, or both) were defined strictly as symptoms at least once a week, present during work days or at night after work in the past 3-6 months, and declining during weekends or holidays; aggravations of pre-existing symptoms have not been included. Also, other work related symptoms - such as throat irritation and fevers, were noted.

Histories of asthma and bronchitis were asked for. Chronic bronchitis was defined as daily productive cough for $>3$ months each year during at least 2 consecutive years. Also, wheezing, shortness of breath, and chest tightness when exposed to physical exertion, cold, 
irritants (tobacco smoke, motor vehicle exhausts, perfumes, solvents or paints, etc) were recorded and considered indicative of nonspecific bronchial hyperresponsiveness.

The employees were examined (throat, nose, heart, lungs, and lymph nodes of the head and neck) by a physician during work days in the factory; baseline spirometries were performed according to the guidelines of the American Thoracic Society (1987). ${ }^{14}$ Vital capacity (VC) and forced exspiratory volume in 1 second $\left(\mathrm{FEV}_{1}\right)$ were measured on a Vitalograph (Vitalograph, Buckingham, UK).

Venous blood and urinary spot samples were collected during work and stored at $-18^{\circ} \mathrm{C}$. Plasma and urine were analysed for isocyanate metabolites, and serum for immunological variables.

Up to five samples of serum and three samples of urine were missing in the analyses.

Neither the examiners, nor the workers, were aware of the biomarker results until after the examinations.

MEASUREMENTS OF ISOCYANATE METABOLITES IN PLASMA AND URINE

Measurements of metabolites in blood and urine of MDI (MDX), TDI (TDX), and HDI (HDX) were made after hydrolysis and derivatisation with pentafluoropropionic acid (PFPA). PFPA-derivatives of 4,4'-methylenedianiline (MDA) and 2,4- and 2,6-toluenediamine (2,4-TDA and 2,6-TDA) were measured by gas chromatography and chemical ionisation mass spectrometry (GC MS) and 1,6-hexammethylenediamine (HDA) by liquid chromatography mass spectrometry (LC MS), both monitoring negative ions. ${ }^{9}{ }^{10} 15$ Dideuterated MDA, trideuterated 2,4-TDA and 2,6TDA, and tetradeuterated HDA were used as internal standards.

Each batch of plasma or urine comprised about 100 samples (for HDA, totally 10 samples) and included two sets of calibration samples, each of which included five concentrations of MDA, 2,4-TDA, 2,6-TDA, or HDA. The mean correlation coefficient for eight standard curves was 0.98 . The mean relative $\mathrm{SD}$ of the slope was $2 \%$. The limit of measurement for MDA and 2,4-TDA and 2,6-TDA was $0.05 \mu \mathrm{g} / 1$ (0.3 and $0.4 \mathrm{nmol} / \mathrm{l}$, respectively), for HDA the limit of measurement was about 10 times higher.

Each plasma and urine sample was divided in two parts (1 and 2), which were dealt with separately. Before injection, the samples were again divided in two (1A and $1 \mathrm{~B}, 2 \mathrm{~A}$ and $2 \mathrm{~B}$ ). If the mean concentration in samples $1 \mathrm{~A}$ and $1 \mathrm{~B}$ or $2 \mathrm{~A}$ and $2 \mathrm{~B}$ differed by $>40 \%$, or $\mathrm{A}$ and $\mathrm{B}$ by $>5 \%$, the results were disregarded, and the samples were reanalysed. For all values $>0.5$ $\mu \mathrm{g} / \mathrm{l}$ in plasma, measurements were repeated. In an international quality control program (German Society for Occupational and Environmental Medicine), our measurements of U-MDA were in excellent agreement with those from the other laboratories.
IMMUNOLOGICAL EXAMINATIONS

Specific serum antibodies against conjugates of MDI, TDI, or HDI and human serum albumin (HSA) were analysed by RAST (IgE) or enzyme linked immunosorbent assay (ELISA) (IgG). ${ }^{10}{ }^{16}$ Serum samples from 17 non-exposed subjects were used as reference. S-IgE-MDI $>0.3 \%$ specific binding was considered positive (highest referent $0.2 \%$ ). Absorbance (A) values higher than the highest referent (for S-IgGMDI 0.12, S-IgG-TDI 0.15, and S-IgG-HDI 0.31 ) were categorised as positive. In some analyses, however, the actual S-IgE-MDI and S-IgG-MDI values were used.

Total serum IgG, IgM, and IgA (S-IgG, S-IgM, S-IgA; measured by turbidometry), as well as circulating immune complexes (S-CIC; $\mathrm{C} 1 \mathrm{q}$-binding assay), antinuclear antibodies (S-ANA; antibodies against Hep-2 cells), C reactive protein (S-CRP; turbidometry), total white blood cell count (Sysmex NE 8 000) and eosinophils (results obtained for only 98 subjects), total serum IgE (S-IgE; Pharmacia CAP), and a serological screening for airborne allergy (Phadiatop-test) were analysed by routine clinical methods.

\section{STATISTICAL METHODS}

Relations between exposure, isocyanate metabolites, and effects were analysed as in the figure.

The effects of sprayed and heated glue on work related symptoms, lung function, metabolites, and antibodies, as well as the effects of lung function, metabolites, and antibodies on work related symptoms in workers were evaluated by logistic regression. ${ }^{17}$ Each symptom was studied separately, and comparisons were made with workers without that specific symptom. The lung function variables $\mathrm{VC}$ and $\mathrm{FEV}_{1}$ (medians $93 \%$ and $97 \%$ predicted, respectively), total serum antibodies IgG, IgM, IgA, and IgE (medians 13.6, 1.2, $2.2 \mathrm{~g} / \mathrm{l}$, and 21 $\mathrm{kU} / 1$, respectively), and P-MDX (median 0.27 $\mu \mathrm{g} / \mathrm{l}$ ) were dichotomised at median values, the other metabolites at the limit of measurement. The specific isocyanate antibodies were dichotomised into positive and negative values.

The effects of spray and heat on the specific antibodies were evaluated with the continuous variables in an analysis of variance (ANOVA). ${ }^{18}$ The variables were log transformed to fulfil the model assumptions.

Sex and age (trichotomised) were always considered as potential confounders, but were adjusted for only if the unadjusted and adjusted estimates differed $\geqslant 15 \%$. As age and employment time were correlated $\left(r_{s}=0.60\right)$, an effect of age may partly reflect an effect of employment time. To examine if glue that was sprayed modified the effect of glue that was heated and vice versa, an interaction term was considered in the models. Moreover, smoking (non-smoker, current smoker, and ex-smoker) and atopy (histories and Phadiatop screening tests) were considered as potential effect modifiers by incorporating interaction terms in the models. Multiplicative effect estimates were obtained, for dichotomous responses as preva- 


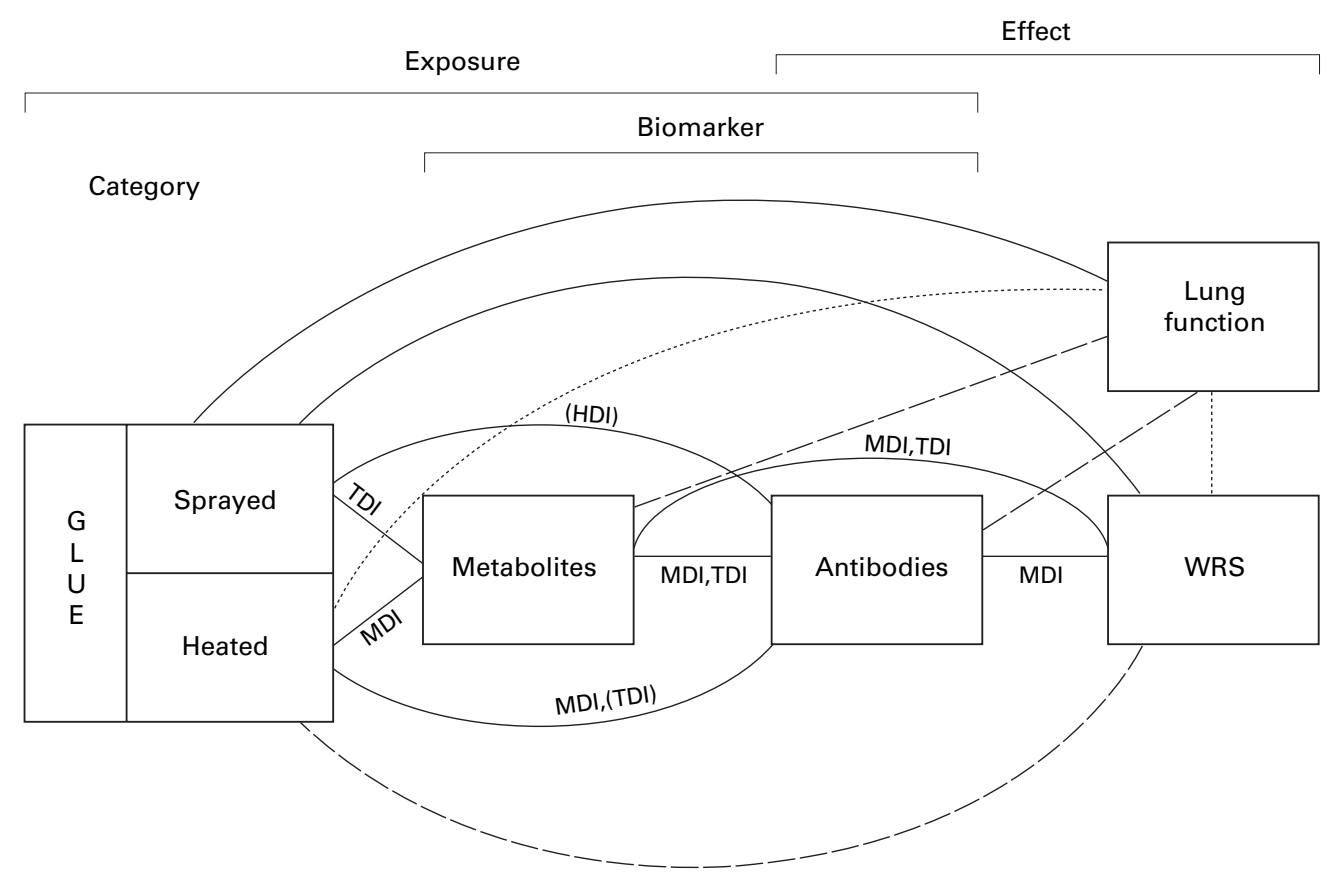

Model for analysis of relation between exposure to sprayed and heated glue, biomarkers, and effects. Significant associations are indicated by full (positive associations) or dotted (negative associations) lines, and non-significant associations by broken lines. $M D I=4,4$-methylene di-isocyanate (MDI); TDI=toluene di-isocyanate; HDI=hexamethylene di-isocyanate.

lence odds ratio (OR) estimates and for continuous response variables as ratios.

When testing trends, the coefficient from a logistic model with the exposure (P-MDX) or effect (S-IgG-MDI, S-IgG, S-IgM) biomarker as an untransformed continuous variable was used as a test statistic.
For statistical testing of continuous variables we used the Mann-Whitney $U$ test, for binary variables Fisher's exact test, and for tests of correlation Spearman's rank correlation coefficient $\left(r_{\mathrm{s}}\right)$.

Significance was defined as $\mathrm{p} \leqslant 0.05$ (two tailed).

Table 2 Concentrations of metabolites in plasma and urine (medians (ranges)), antibodies (medians (ranges)), work related symptoms (number of subjects), and lung function measurements (medians (ranges)) in 14 clerks and 152 workers, potentially exposed to sprayed or heated polyurethane glue

\begin{tabular}{|c|c|c|c|c|c|c|c|}
\hline \multirow[b]{4}{*}{ Effect/biomarker } & \multirow[b]{4}{*}{ Clerks } & \multicolumn{6}{|l|}{ Workers } \\
\hline & & \multirow[b]{3}{*}{$(\% M)$} & \multirow[b]{3}{*}{ Total } & \multicolumn{4}{|l|}{ Sprayed glue } \\
\hline & & & & \multicolumn{2}{|l|}{ No Heat } & \multicolumn{2}{|l|}{ Yes Heat } \\
\hline & & & & No $(n=71)$ & Yes $(n=32)$ & No $(n=4)$ & Yes $(n=45)$ \\
\hline \multicolumn{8}{|l|}{ Metabolites ${ }^{\star}$ : } \\
\hline P-MDX & $\mathrm{LM}$ & 65 & $0.27(\mathrm{LM}-18)$ & $\mathrm{LM}(\mathrm{LM}-1.8)$ & $0.64(\mathrm{LM}-7.9)$ & $0.42(\mathrm{LM}-0.9)$ & $0.89(\mathrm{LM}-18)$ \\
\hline U-MDX & $\mathrm{LM}$ & 11 & LM (LM-9.4) & $\mathrm{LM}(\mathrm{LM}-4.7)$ & $\mathrm{LM}(\mathrm{LM}-1.8)$ & $\mathrm{LM}(\mathrm{LM}-2.1)$ & LM (LM-9.4) \\
\hline P-2,4-TDX & $\mathrm{LM}$ & 16 & $\mathrm{LM}(\mathrm{LM}-1.7)$ & $\mathrm{LM}(\mathrm{LM}-0.4)$ & $\mathrm{LM}(\mathrm{LM}-0.4)$ & $\mathrm{LM}(\mathrm{LM}-0.3)$ & $\mathrm{LM}(\mathrm{LM}-1.7)$ \\
\hline U-2,4-TDX & LM & 47 & $\mathrm{LM}(\mathrm{LM}-11)$ & $\mathrm{LM}(\mathrm{LM}-11)$ & LM (LM-2.7) & $0.35(\mathrm{LM}-1.4)$ & LM (LM-2.7) \\
\hline P-2,6-TDX & $\mathrm{LM}$ & 7 & $\mathrm{LM}(\mathrm{LM}-0.9)$ & $\mathrm{LM}(\mathrm{LM}-0.2)$ & $\mathrm{LM}(\mathrm{LM}-\mathrm{LM})$ & $\mathrm{LM}(\mathrm{LM}-\mathrm{LM})$ & $\mathrm{LM}(\mathrm{LM}-0.9)$ \\
\hline U-2,6-TDX & $\mathrm{LM}$ & 5 & $\mathrm{LM}(\mathrm{LM}-0.8)$ & $\mathrm{LM}(\mathrm{LM}-0.3)$ & $\mathrm{LM}(\mathrm{LM}-0.1)$ & $\mathrm{LM}(\mathrm{LM}-\mathrm{LM})$ & $\mathrm{LM}(\mathrm{LM}-0.8)$ \\
\hline \multicolumn{8}{|l|}{ Antibodies ${ }^{\star}$ : } \\
\hline S-IgG-MDI & 0.10 & 97 & $0.10(0.02-1.1)$ & $0.09(0.02-0.4)$ & $0.10(0.02-0.4)$ & $0.08(0.08-0.09)$ & $0.13(0.06-1.1)$ \\
\hline S-IgG-TDI & 0.10 & 97 & $0.13(0.05-0.8)$ & $0.11(0.05-0.3)$ & $0.13(0.07-0.4)$ & $0.10(0.08-0.12)$ & $0.15(0.05-0.8)$ \\
\hline S-IgG-HDI & 0.16 & 97 & $0.14(0-1.1)$ & $0.12(0.02-0.8)$ & $0.13(0-0.5)$ & $0.17(0.05-0.34)$ & $0.21(0.06-1.1)$ \\
\hline S-IgE-MDI & 0 & 97 & $0(0-5.3)$ & $0(0-5.3)$ & $0(0-1.4)$ & $0(0-0)$ & $0(0-0.7)$ \\
\hline S-IgG & 11 & 97 & $14(8.3-23)$ & $14(8.3-20)$ & $13(8.6-20)$ & $16(9.8-22)$ & $15(9.8-23)$ \\
\hline S-IgM & 1.1 & 97 & $1.2(0.3-3)$ & $1.1(0.3-2.8)$ & $1.4(0.3-2.4)$ & $1.3(0.8-2.2)$ & $1.4(0.3-3)$ \\
\hline S-IgA & 2.7 & 97 & $2.2(0.5-5.3)$ & $2.3(0.9-5.3)$ & $2.0(1.2-4.9)$ & $2.4(1.7-4.3)$ & $2.2(0.5-4)$ \\
\hline S-IgE & 64 & 97 & $21(1-2000)$ & $20(1-2000)$ & $29(1-210)$ & $20(3-360)$ & $17(2-220)$ \\
\hline \multicolumn{8}{|c|}{ Work related symptoms: } \\
\hline Total $(\mathrm{n}(\%))$ & 0 & 100 & $47(31)$ & $14(20)$ & $9(28)$ & $3(75)$ & $21(47)$ \\
\hline Eyes & - & - & $21(14)$ & $7(10)$ & $6(19)$ & $2(50)$ & $6(13)$ \\
\hline Airways & - & - & $40(26)$ & $13(18)$ & $8(25)$ & $1(25)$ & $18(40)$ \\
\hline Nose & - & - & $32(21)$ & $12(17)$ & $6(19)$ & $1(25)$ & $13(29)$ \\
\hline Lower & - & - & $17(11)$ & $5(7)$ & $4(12)$ & $0(0)$ & $8(18)$ \\
\hline \multicolumn{8}{|l|}{ Lung function ${ }^{\star}$ : } \\
\hline $\mathrm{VC}$ & 94 & 99 & $93(63-130)$ & $93(72-130)$ & $100(78-129)$ & $94(82-128)$ & $90(63-124)$ \\
\hline $\mathrm{FEV}_{1}$ & 99 & 99 & $97(67-130)$ & $95(67-126)$ & $102(70-130)$ & $98(79-128)$ & $94(72-124)$ \\
\hline
\end{tabular}

${ }^{\star} \mathrm{P}-\mathrm{MDX}$ and $\mathrm{U}-\mathrm{MDX}=$ metabolites of 4,4'-diphenylmethane diisocyanate (MDI), P-2,4-TDX and U-2,4-TDX and P-2,6-TDX and U-2,6-TDX=metabolites of 2,4-toluene diisocyanate (TDI) and 2,6-TDI in plasma and urine ( $\mu \mathrm{g} / 1)$; S-IgG-MDI, S-IgG-TDI, S-IgG-HDI, and S-IgE-MDI=specific serum IgG (A) and IgE (\% binding) antibodies against MDI, TDI, and hexamethylene diisocyanate; S-IgG, S-IgM, S-IgA, S-IgE = total serum IgG, IgM, IgA (g/l), and IgE (kU/1) antibodies. $\mathrm{VC}=$ vital capacity, $\mathrm{FEV}_{1}=$ forced exspiratory volume in 1 second $(\%$ predicted).

$(\% \mathrm{M})=\%$ of workers with measurable values; $\mathrm{LM}=1$ imit of measurement $=\leqslant 0.05 \mu \mathrm{g} / \mathrm{l}$. 


\section{Results}

EXPOSURE AND METABOLITES

All clerks had P-MDX $\leqslant 0.05 \mu \mathrm{g} / \mathrm{l}$ (limit of measurement; table 2). Among the workers, this limit was exceeded in $65 \%$, among glue users in $85 \%$. In an attempt to separately assess the effects of exposure to aerosol or vapour from glue that was sprayed and glue that was heated, the workers were divided according to those conditions (figure and tables 1 and 2). Heating had a pronounced effect on P-MDX, especially when carried out by guns (gun $v$ non-gun heating: medians $0.80 v 0.54 \mu \mathrm{g} / \mathrm{l}$; not in table). The highest concentrations were found in workers both spraying and heating (table 2). Again, the effect of gun heating exceeded that of other heating methods (medians $1.8 v 0.11 \mu \mathrm{g} / 1 ; \mathrm{p} \leqslant 0.0001$; not in table).

There was a similar pattern for U-MDX, also on the effect of heat guns; however, the concentrations were above the limit of measurement in only $11 \%$ of all workers (table 2).

P-2,4-TDX and P-2,6-TDX exceeded the limit of measurement in $16 \%$ and $7 \%$ of the workers, respectively, but in none of the clerks (table 2). Three clerks (21\%) had U-TDXs above the limit of measurement (U-2,4-TDX up to $9.3 \mu \mathrm{g} / \mathrm{l}$ ) versus $48 \%$ of the workers (ps=0.1; not shown).

There was an effect of spraying on both P-TDX metabolites (figure; tables 2 and 3); workers who heated with guns instead of with other methods had higher P-2,4-TDX (medians $0.11 v \mathrm{LM} \mu \mathrm{g} / \mathrm{l} ; \mathrm{p}=0.01$; not shown). For U-TDX, there were no significant associations.

Nine women making arm rests had intense spraying and gun heating tasks particularly often; they had the highest P-MDX concentrations (median (range) $13(2.6-18) \mu \mathrm{g} / \mathrm{l})$, U-MDX (median $3.3 \mu \mathrm{g} / \mathrm{l}$ ), P-2,4-TDX and U-2,4-TDX $(0.6 \mu \mathrm{g} / \mathrm{l})$, and P-2,6-TDX (0.5 $\mu \mathrm{g} / 1)$ ), all significantly $(\mathrm{p} \leqslant 0.001$; not shown) higher than in other workers.

P-HDX and U-HDX were not detected in any plasma or urine samples (not in table).

All the exposure biomarkers, except P-MDX/U-2,6-TDX, were correlated $\left(r_{s}=0.15-0.53 ; \mathrm{p}<0.0001-0.05\right)$.

Twenty one workers with a history of atopy had slightly lower P-MDX than those without such a history ( medians $0.11 v 0.35 \mu \mathrm{g} / \mathrm{l}$; $\mathrm{p}=0.06$; not shown)

\section{EXPOSURE AND EFFECTS}

Antibodies

Four employees, all workers, were positive for S-IgE-MDI (not in table). They were also S-IgG-MDI positive.

Four clerks $(28 \%)$ were positive for S-IgGMDI and S-IgG-TDI; two were positive for S-IgG-HDI (not in table). In all, six (43\%) were positive for at least one of the specific isocyanate antibodies; two of them reported airways symptoms at work, but could not state how often (so they did not fulfil our definition of work related symptoms which should be present at least once a week).

Among the workers, $45 \%$ were positive for at least one of the specific IgG antibodies, 55\%
Table 3 Estimated effects (obtained from a multivariate logistic regression; OR (95\% CI)) of exposure to sprayed (dichotomised into yes and no) or heated (dichotomised into yes and no) polyurethane glue in 152 workers on concentrations of metabolites, antibodies, work related symptoms, and lung function measurements

\begin{tabular}{|c|c|c|}
\hline & $\begin{array}{l}\text { Sprayed glue } \\
\text { OR }(95 \% \text { CI) }\end{array}$ & $\begin{array}{l}\text { Heated glue } \\
\text { OR }(95 \% \text { CI) }\end{array}$ \\
\hline \multicolumn{3}{|l|}{ Metabolites ${ }^{\star}:$} \\
\hline P-MDX† & $0.72(0.26$ to 2.0$)$ & 12 (4.4 to 30$)$ \\
\hline U-MDX $\ddagger$ & $2.2(0.7$ to 77$)$ & $2.2(0.5$ to 8.9$)$ \\
\hline P-2,4-TDX $\ddagger$ & 6.2 (1.8 to 22$)$ & $1.1(0.30$ to 4.1$)$ \\
\hline $\mathrm{U}-2,4-\mathrm{TDX} \ddagger$ & $1.3(0.60$ to 3.1$)$ & $0.70(0.30$ to 1.6$)$ \\
\hline P-2,6-TDX $\ddagger$ & 16 (1.4 to 180$)$ & $1.9(0.20$ to 23$)$ \\
\hline $\mathrm{U}-2,6-\mathrm{TDX} \ddagger$ & $2.3(0.30$ to 15$)$ & $1.5(0.20$ to 12$)$ \\
\hline \multicolumn{3}{|l|}{ Antibodies*: } \\
\hline S-IgG-MDI & $1.1(0.45$ to 2.6$)$ & $3.7(1.4$ to 9.5$)$ व \\
\hline S-IgG-TDIS & $1.5(0.64$ to 3.6$)$ & $1.5(0.59$ to 3.6$)$ \\
\hline S-IgG-HDI & $3.6(0.92$ to 14$) \pi$ & $1.7(0.36$ to 8.2$)$ \\
\hline S-IgE-MDIS & & \\
\hline S-IgG $\dagger$ & $2.4(1.0$ to 5.8$)$ & $0.97(0.43$ to 2.1$)$ \\
\hline S-IgM† & 1.5 (0.65 to 3.5$)$ & 1.3 (0.56 to 3.1$)$ \\
\hline S-IgAt & $1.3(0.57$ to 3.1$)$ & $0.62(0.28$ to 1.4$)$ \\
\hline S-IgE† & $0.55(0.24$ to 1.3$)$ & $1.5(0.67$ to 3.3$)$ \\
\hline \multicolumn{3}{|c|}{ Work related symptoms: } \\
\hline Total & $3.0(1.2$ to 7.4$)$ & $1.2(0.49$ to 2.9$)$ \\
\hline Eyes & $1.2(0.37$ to 3.8$)$ & $0.85(0.27$ to 2.7$)$ \\
\hline Airways & $1.9(0.77$ to 4.7$)$ & $1.6(0.63$ to 3.9$)$ \\
\hline Nose & $1.7(0.64$ to 4.7$)$ & $1.2(0.43$ to 3.1$)$ \\
\hline & $1.3(0.39$ to 4.4$)$ & $2.2(0.61$ to 8.1$)$ \\
\hline \multicolumn{3}{|l|}{ Lung function ${ }^{\star}$ : } \\
\hline VC† & $3.0(1.3$ to 7.3$)$ & $0.49(0.22$ to 1.1$)$ \\
\hline $\mathrm{FEV}_{1} \dagger$ & $4.2(1.6$ to 11$)$ & $0.29(0.12$ to 0.70$)$ \\
\hline
\end{tabular}

${ }^{\star} \mathrm{P}-\mathrm{MDX}$ and U-MDX $=$ metabolites of 4,4'-diphenylmethane diisocyanate (MDI), P-2,4-TDX and U-2,4-TDX and P-2,6TDX and U-2,6-TDX=metabolites of 2,4-toluene diisocyanate and 2,6-toluene disocyanate (TDI) in plasma and urine; S-IgG-MDI, S-IgG-TDI, S-IgG-HDI, and S-IgEMDI=specific serum antibodies against MDI, TDI, and hexamethylene diisocyanate; S-IgG, S-IgM, S-IgA, S-IgE=total serum IgG, IgM, IgA, and IgE antibodies; VC=vital capacity, $\mathrm{FEV}_{1}=$ forced exspiratory volume in 1 second.

$\dagger$ Dichotomised at median value.

$\ddagger$ Dichotomised at the limit of measurement.

$\$$ Dichotomised into positive and negative values.

ๆAdjusted for age and sex.

among the glue users (not in table). Thirty three per cent were S-IgG-MDI positive. Workers who heated glues had increased concentrations (figure; tables 2 and 3). Also, in a multivariate parametric analysis (antibodies as continuous variables), the workers who heated glues had a 30\% increase (95\% CI $4 \%-64 \%$; not in table); in such an analysis, sprayers had a $23 \%$ increase. The values were highest in workers who both sprayed and used heat (table 2).

Specific S-IgG-TDI was positive in $32 \%$ of all workers. Those spraying and those heating glue had slightly, not significantly, higher levels than the others (figure; tables 2 and 3 ). In a multivariate analysis, the levels in workers who heated glues were $24 \%$ higher (95\% CI $5 \%-47 \%$ ).

Only $12 \%$ of the workers were positive for $\mathrm{S}-\mathrm{IgG}-\mathrm{HDI}$. The values were highest in sprayers (figure; tables 2 and 3). Multivariate analysis showed a $41 \%$ increase $(95 \%$ CI $10 \%-90 \%$ ) from glue spraying (not in table). In particular, workers ever using glues containing HDI themselves $(n=22)$ had higher S-IgGHDI than the others (medians $0.24 v 0.13 \mathrm{~A}$; $\mathrm{p} \leqslant 0.0001)$.

Total S-IgG was increased in sprayers (tables 2 and 3). S-IgM, S-IgA, and S-IgE were not associated with any one of the exposure categories. 
Table 4 Work related symptoms in eyes, nose, lower airways, and airways (nose or lower airways, or both) and estimated effects (OR (95\% CI)) of metabolites, antibodies and lung function in 152 workers, potentially exposed to sprayed or heated polyurethane glue

\begin{tabular}{|c|c|c|c|c|c|c|c|c|c|}
\hline \multirow[b]{3}{*}{ Biomarker* } & \multicolumn{9}{|c|}{ Work related symptoms } \\
\hline & \multirow{2}{*}{$\begin{array}{l}\text { None } \\
\text { Median }\end{array}$} & \multicolumn{2}{|c|}{ Eyes $(n=21)$} & \multicolumn{2}{|c|}{ Nose $(n=32)$} & \multicolumn{2}{|c|}{ Lower airways $(n=17)$} & \multicolumn{2}{|c|}{ Airways $(n=40)$} \\
\hline & & Median & OR $(95 \% C I$ & Median & OR $(95 \% C I)$ & Median & OR $(95 \% C I)$ & Median & OR $(95 \% C I)$ \\
\hline P-MDX† & 0.26 & 0.17 & $0.60(0.22$ to 1.6$)$ & 0.38 & 0.88 (0.38 to 2.0$)$ - & 0.57 & $1.0(0.35$ to 3.1$)$ & 0.48 & 0.98 (0.45 to 2.2$)$ \\
\hline $\mathrm{U}-\mathrm{MDX} \ddagger$ & $\mathrm{LM}$ & $\mathrm{LM}$ & $0.80(0.17$ to 3.8$)$ & $\mathrm{LM}$ & $2.2(0.76$ to 6.6$)$ & $\mathrm{LM}$ & $4.2(1.3$ to 14$)$ & $\mathrm{LM}$ & $3.7(1.3$ to 10$)$ \\
\hline P-2,4-TDX $\ddagger$ & $\mathrm{LM}$ & $\mathrm{LM}$ & $0.94(0.25$ to 3.5$)$ & $\mathrm{LM}$ & $0.72(0.23$ to 2.3$)$ & $\mathrm{LM}$ & $1.8(0.53$ to 6.1$)$ & $\mathrm{LM}$ & $1.2(0.46$ to 3.2$)$ \\
\hline $\mathrm{U}-2,4-\mathrm{TDX} \ddagger$ & $\mathrm{LM}$ & 0.20 & $1.3(0.50$ to 3.2$)$ & 0.20 & $1.3(0.61$ to 2.9$)$ & $\mathrm{LM}$ & $0.57(0.20$ to 1.6$)$ & $\mathrm{LM}$ & $1.0(0.49$ to 2.1$)$ \\
\hline P-2,6-TDX $\ddagger$ & $\mathrm{LM}$ & $\mathrm{LM}$ & $1.3(0.25$ to 6.9$)$ & $\mathrm{LM}$ & $0.89(0.18$ to 4.4$)$ & $\mathrm{LM}$ & $6.4(1.6$ to 26$)$ & $\mathrm{LM}$ & $2.9(0.80$ to 11$)$ \\
\hline U-2,6-TDX $\ddagger$ & $\mathrm{LM}$ & $\mathrm{LM}$ & 0 & $\mathrm{LM}$ & 0 & $\mathrm{LM}$ & $3.4(0.61$ to 19$)$ & $\mathrm{LM}$ & $1.1(0.21$ to 5.9$)$ \\
\hline S-IgG-MDIS & 0.10 & 0.10 & $0.69(0.24$ to 2.0$)$ & 0.12 & $2.4(1.1$ to 5.3$)$ & 0.13 & $2.6(0.94$ to 7.3$)$ & 0.12 & $2.6(1.2$ to 5.5$)$ \\
\hline S-IgG-TDIS & 0.12 & 0.12 & $0.48(0.16$ to 1.5$)$ व & 0.15 & $1.7(0.77$ to 3.9$)$ & 0.13 & $1.6(0.56$ to 4.4$)$ & 0.14 & $1.7(0.81$ to 3.7$)$ \\
\hline S-IgG-HDIS & 0.13 & 0.16 & $2.2(0.64$ to 7.6$)$ & 0.17 & $1.2(0.35$ to 3.9$)$ & 0.22 & $1.8(0.45$ to 7.0$)$ & 0.21 & $2.1(0.75$ to 6.1$)$ \\
\hline S-IgE-MDIS & 0 & 0 & - & 0 & - & 0 & - & 0 & - \\
\hline S-IgG† & 13 & 13 & $0.66(0.24$ to 1.8$)$ & 15 & $2.1(0.95$ to 4.7$)$ & 15 & $2.2(0.76$ to 6.2$)$ & 15 & $1.9(0.93$ to 4.1$)$ \\
\hline S-IgM + & 1.2 & 1.6 & $3.9(1.3$ to 11$)$ & 1.4 & $1.7(0.75$ to 4.0$)$ & 1.6 & $4.1(1.3$ to 13$)$ & 1.4 & $2.6(1.2$ to 5.5$)$ \\
\hline S-IgAt & 2.1 & 2.0 & $1.69(0.26$ to 1.8$)$ & 2.2 & $0.94(0.43$ to 2.1$)$ & 2.3 & $1.2(0.46$ to 3.4$)$ & 2.2 & $0.97(0.47$ to 2.0$)$ \\
\hline S-IgE† & 20 & 20 & $1.0(0.40$ to 2.6$)$ & 20 & $0.74(0.34$ to 1.6$)$ & 36 & $1.5(0.54$ to 4.2$)$ & 22 & $1.0(0.49$ to 2.1$)$ \\
\hline $\mathrm{VC} \dagger$ & 92 & 95 & - & 95 & $0.79(0.36$ to 1.7$)$ & 97 & $0.54(0.19$ to 1.5$)$ & 95 & $0.80(0.38$ to 1.7$)$ \\
\hline $\mathrm{FEV}_{1} \dagger$ & 96 & 100 & - & 99 & $0.73(0.33$ to 1.6$)$ & 104 & $0.21(0.06$ to 0.77$)$ & 100 & $0.60(0.29$ to 1.3$)$ \\
\hline
\end{tabular}

${ }^{\star} \mathrm{P}-\mathrm{MDX}$ and $\mathrm{U}-\mathrm{MDX}=$ metabolites of 4,4'-diphenylmethane diisocyanate (MDI), P-2,4-TDX and U-2,4-TDX and P-2,6-TDX and U-2,6-TDX=metabolites of 2,4-toluene diisocyanate and 2,6-toluene diisocyanate (TDI; $\mu \mathrm{g} / \mathrm{l}$ ) in plasma and urine; S-IgG-MDI, S-IgG-TDI, S-IgG-HDI, and S-IgE-MDI=specific serum IgG (A) and IgE (\%binding) antibodies against MDI, TDI, and hexamethylene diisocyanate; S-IgG, S-IgM, S-IgA, S-IgE=total serum IgG, IgM, IgA (g/L), and IgE (kU/l) antibodies; $\mathrm{VC}=$ vital capacity, $\mathrm{FEV}_{1}=$ forced exspiratory volume in one second ( $\%$ predicted); $\mathrm{LM}=$ limit of measurement $=\leqslant 0.05 \mu \mathrm{g} / 1$. Clerks had no work related symptoms.

†Dichotomised at median value.

$\ddagger$ Dichotomised at the limit of measurement.

SDichotomised into positive and negative values.

TAdjusted for age and sex.

The nine arm rest workers, who used both glues based on MDI and HDI every work day, had particularly high concentrations of S-IgGMDI (median 0.41 A), S-IgG-HDI (0.44 A), S-IgG-TDI (0.2 A), and S-IgG (16 g/l), all significantly higher than in other workers ( $p \leqslant 0.01$; not shown).

There were slight associations between P-MDX and S-IgG-MDI and S-IgG-TDI (both $r_{s}=0.21 ; p<0.01$ ), and total S-IgG and S-IgM $\quad\left(r_{s}=0.25\right.$ and 0.23 , respectively; $\mathrm{p} \leqslant 0.004)$. The TDI metabolites, in particular P-2,6-TDX, correlated slightly with all three specific antibodies, and with total S-IgG and S-IgM ( $\left.\mathrm{r}_{\mathrm{s}}=0.15-0.22 ; \mathrm{p}<0.01-0.05\right)$.

$\mathrm{S}-\mathrm{IgE}-\mathrm{MDI}$ showed a minor correlation with $S-\operatorname{IgE}$ and with eosinophils $\left(r_{s}=0.15\right.$ and 0.22 , respectively; $\mathrm{p} \leqslant 0.05)$. The IgG antibodies against MDI, TDI, and HDI were correlated $\left(r_{s}=0.54-0.64 ; \mathrm{p}<0.0001\right)$. Total $\mathrm{S}-\mathrm{IgG}$ was very slightly correlated with the specific antibodies $\left(r_{s}=0.16-0.21 ; p \leqslant 0.05\right)$. No such correlations were found for S-IgM or S-IgA.

Neither atopy nor smoking was associated with increased risks of formation of specific $\operatorname{IgE}$ or IgG antibodies. However, workers with an atopic history had lower S-IgG-MDI than those without (medians 0.08 v $0.11 \quad \mathrm{~A}$; $\mathrm{p}=0.004$; not shown).

Work related symptoms

Among the workers, $26 \%$ had work related symptoms of the airways (table 2), $15 \%$ from the nose only, $5 \%$ from lower airways only, and $6 \%$ from both. Within the lower airways group, nine workers reported dyspnoea, wheezing, or chest tightness, and nine severe dry cough; one worker had both dyspnoea and cough.

Use of glue was associated with work related symptoms $\quad(33 / 81=41 \% \quad v \quad 14 / 71=20 \%$; $\mathrm{OR}=2.8$ (95\% CI 1.3 to 5.8); not shown). Spraying of glue had an effect on total work related symptoms, but not on work related symptoms of the lower airways (table 3). We could not show any significant effect of heating all kinds of glues and there were no significant interactions between spraying and heating (not in table). However, among workers who heated glues, use of heat guns compared with use of other heat was associated with a nonsignificant risk of work related symptoms $(8 / 23=35 \%$ o $1 / 9=11 \%)$ and work related symptoms of the airways ( $35 \% v 0 \%$ ); the same pattern was found among sprayers who used different heating methods (work related symptoms: $54 \% v 37 \%$, work related symptoms of the airways: $50 \% v 26 \%$ ).

Atopy or smoking did not significantly modify the effects.

\section{Lung function}

The spirometric values did not differ between workers who used glue and others (not shown), but spraying of glue was significantly associated with a slightly reduced lung function (tables 2 and 3). Unexpectedly, workers who heated glue had a somewhat better lung function than the others. Further, surprisingly, $\mathrm{FEV}_{1}$ was slightly improved among those with work related symptoms of the lower airways (table 4).

BIOMARKERS OF EXPOSURE AND EFFECTS Metabolites versus work related symptms

In workers with work related symptoms of the airways, P-MDX was higher than in those without such symptoms, but not significantly so (figure; tables 4 and 5). Moreover, when work related symptoms of the airways was analysed with P-MDX as a continuous variable (limit of measurement $0.025 \mu \mathrm{g} / \mathrm{l}$ ), there was an increased risk with rising concentrations $(\mathrm{OR}=1.1 / \mu \mathrm{g} / \mathrm{l} ; 95 \%$ CI 1.0 to 1.2 ; not in table). Also, in those 15 workers with concentrations of P-MDX >90th percentile $(3.8 \mu \mathrm{g} / \mathrm{l})$, as many as $53 \%$ had work related symptoms of the airways, which corresponds to an OR of 3.6 (95\% 
Table 5 Work related symptoms and concentrations of metabolites of 4,4'-diphenylmethane diisocyanate (MDI; $P$-MDX) in plasma and of specific IgG against MDI (S-IgG-MDI) and total serum immunoglobulins IgG and IgM in 152 workers potentially exposed to sprayed or heated polyurethane glue (OR (95\% CI))

\begin{tabular}{|c|c|c|c|c|c|}
\hline & \multicolumn{5}{|c|}{ Work related symptoms $\mathrm{OR}(95 \% \mathrm{CI})^{*}$} \\
\hline & \multirow[b]{2}{*}{ Eyes $(n=21)$} & \multicolumn{3}{|l|}{ Airways } & \multirow[b]{2}{*}{ All $(n=47)$} \\
\hline & & Nose $(n=32)$ & $\begin{array}{l}\text { Lower } \\
\text { airways }(n=17)\end{array}$ & Total $(n=40)$ & \\
\hline \multicolumn{6}{|l|}{ P-MDX ( $\mu \mathrm{g} / \mathrm{l}):$} \\
\hline$\leqslant \mathrm{LM}$ & $1.0 \dagger$ & $1.0 \dagger$ & $1.0 \dagger$ & $1.0 \dagger$ & $1.0 \dagger$ \\
\hline$>\mathrm{LM}-0.60$ & $0.33(0.08$ to 1.3$)$ & $1.3(0.46$ to 3.9$)$ & $3.6(0.66$ to 20$)$ & $1.5(0.55$ to 4.2$)$ & $0.91(0.35$ to 2.4$)$ \\
\hline$>0.60-18$ & $0.51(0.16$ to 1.6$)$ & $1.3(0.45$ to 3.9$)$ & $3.4(0.61$ to 19$)$ & $2.0(0.71$ to 5.4$)$ & $1.3(0.52$ to 3.4$)$ \\
\hline $\mathrm{p}$ Value for trend & 0.3 & 0.6 & 0.2 & 0.2 & 0.5 \\
\hline \multicolumn{6}{|l|}{ S-IgG-MDI (A): } \\
\hline $0-0.08$ & $1.0 \dagger$ & 1.0 & $1.0 \dagger$ & 1.0 & 1.0 \\
\hline $0.09-0.12$ & $3.2(0.90$ to 11$)$ & $1.5(0.52$ to 4.5$)$ & $8.2(1.0$ to 70$)$ & $1.9(0.69$ to 5.1$)$ & $2.2(0.87$ to 5.4$)$ \\
\hline $0.13-1.1$ & $1.3(0.34$ to 5.3$)$ & $2.9(1.1$ to 8.0$)$ & $9.7(1.2$ to 81$)$ & $3.6(1.4$ to 9.3$)$ & $2.8(1.1$ to 68$)$ \\
\hline $\mathrm{p}$ Value for trend & 0.7 & 0.03 & 0.03 & 0.007 & 0.03 \\
\hline \multicolumn{6}{|l|}{ S-IgG (g/l): } \\
\hline $0-12.3$ & $1.0 \dagger$ & 1.0 & 1.0 & 1.0 & $1.0 \dagger$ \\
\hline $12.4-14.8$ & $1.0(0.32$ to 3.4$)$ & $2.1(0.70$ to 6.1$)$ & $8.0(0.94$ to 68$)$ & $2.6(1.0$ to 7.2$)$ & $1.4(0.56$ to 3.7$)$ \\
\hline $14.9-23$ & $0.68(0.19$ to 2.4$)$ & $3.1(1.1$ to 8.7$)$ & $11(1.3$ to 86$)$ & $3.4(1.3$ to 9.0$)$ & $2.4(0.96$ to 6.1$)$ \\
\hline $\mathrm{p}$ Value for trend & 0.5 & 0.03 & 0.02 & 0.02 & 0.06 \\
\hline \multicolumn{6}{|l|}{ S-IgM (g/l): } \\
\hline $0-0.9$ & 1.0 & $1.0 \dagger$ & $1.0 \dagger$ & $1.0 \dagger$ & 1.0 \\
\hline $1.0-1.5$ & $1.1(0.27$ to 4.3$)$ & $0.97(0.34$ to 2.8$)$ & $1.3(0.28$ to 5.8$)$ & $1.3(0.51$ to 3.5$)$ & $1.5(0.61$ to 3.8$)$ \\
\hline $1.6-2.4$ & $3.4(1.0$ to 12$)$ & $1.7(0.63$ to 4.8$)$ & $2.8(0.69$ to 12$)$ & $2.0(0.77$ to 5.4$)$ & $2.8(1.2$ to 7.1$)$ \\
\hline $\mathrm{p}$ Value for trend & 0.04 & 0.3 & 0.12 & 0.14 & 0.02 \\
\hline
\end{tabular}

*When at least one OR in a trend series differs $\geqslant 15 \%$ between the unadjusted and the age- and sex-adjusted effect estimates, the adjusted ORs have been given for the whole series.

†Adjusted ORs.

$\mathrm{LM}=$ limit of measurement.

CI 1.03 to 12.4 ). Further, for U-MDX, high concentrations were associated with increased risks (table 4).

Also, workers with high P-2,6-TDX had an increased risk of work related symptoms of the lower airways (table 4), whereas the other TDI metabolites showed no relations.

In those workers reporting cough as a work related symptom of the lower airways, but not in those reporting dyspnoea etc, P-MDX (median $1.32 \mu \mathrm{g} / \mathrm{l}$ ), U-MDX (median LM $\mu \mathrm{g} / \mathrm{l}), \mathrm{P}-2,6-\mathrm{TDX}(\mathrm{LM} \mu \mathrm{g} / \mathrm{l})$, and U-2,6-TDX $(\mathrm{LM} \mu \mathrm{g} / \mathrm{l})$ were all significantly increased compared with other workers ( $p \leqslant 0.05$; not shown).

Metabolites versus lung function

No associations were found between metabolites and lung function, except for a slight correlation between P-2,4-TDX and VC in female workers ( $\%$ predicted; $\left.r_{s}=-0.21 ; p=0.02\right)$.

Antibodies versus work related symptoms One of the four workers with positive S-IgEMDI reported work related symptoms (of the dyspnoea type in lower airways).

Among the workers with high S-IgG-MDI, the risks of work related symptoms of the nose, work related symptoms of the lower airways, and work related symptoms of the airways were increased (figure; tables 4 and 5). Slight non-significant associations were found for S-IgG-TDI and S-IgG-HDI (table 4). Interestingly, those in the lower airways subgroup with cough, but not those with dyspnoea etc, had increased S-IgG-MDI (median 0.14 A; $\mathrm{p}=0.01$; not in table), S-IgG-TDI $(0.18 \mathrm{~A}$; $\mathrm{p}=0.02), \mathrm{S}-\mathrm{IgG}-\mathrm{HDI}(0.22 \mathrm{~A} ; \mathrm{p}=0.03)$, and S-IgG $(16.3 \mathrm{~g} / \mathrm{l} ; \mathrm{p}=0.006)$ compared with other workers.

Among the arm rest workers with high biomarkers, $56 \%$ had work related symptoms, compared with $29 \%$ among other workers.
Workers with high S-IgM had an increased risk of work related symptoms of the eyes, work related symptoms of the lower airways, and work related symptoms of the airways (table 4). Further, there were dose-response relations (table 5). These were also found for S-IgG. No risks were associated with total S-IgA or S-IgE.

Antibodies versus lung function

There were no significant correlations between the specific antibodies and the lung function variables (not shown).

Other

Short term ( $\leqslant 12$ months) workers had reduced spirometric values (median (range) \% predicted): VC 85 (70-95) v 94 (63-130); $\mathrm{p}=0.01$ by Mann-Whitney $U$ test; $\mathrm{FEV}_{1} 87$ (72-100) v 97 (67-130); $\mathrm{p}=0.005$; not shown) and half of them had work related symptoms, compared with $30 \%$ of the others.

White blood cell counts, S-CIC, S-ANA, and S-CRP were evenly distributed among workers with different work tasks, and among workers with and without work related symptoms. No significant correlations with the metabolites or specific S-IgGs or S-IgE-MDI were found for any one of these serum variables.

Use of respiratory or skin protective devices had no significant effect on work related symptoms or on the levels of the biomarkers (not shown).

\section{Discussion}

The most important findings were the relations between exposures to sprayed and heated PUR glue based on MDI and HDI, concentrations of metabolites of MDI and TDI in plasma and urine, specific IgG serum antibodies against MDI, TDI, and HDI, and work related respiratory symptoms. 
However, the exposures are not unambiguously defined. There was an exposure to di-isocyanate monomers, both through the sprayed and the heated glue, but it was low, ${ }^{10}$ corresponding to less than $10 \%$ of the Swedish occupational threshhold limit values (TLVs; MDI 50, HDI 30, and TDI $40 \mu \mathrm{g} / \mathrm{m}^{3}$, respectively). However, the aerosol or vapour of heated glue contains other, less well defined, potentially confounding monoisocyanates, diisocyanates, and aminoisocyanates, the toxicities of which are unknown, as well as amines. ${ }^{911}$ We used the terms MDX, TDX, and HDX to denote the compounds found as MDA, TDA, and HDA after hydrolysis. ${ }^{915} 19$ The same concentration of metabolite in a glue sprayer and in a worker who heated glue may be the result of different exposures (isocyancites, amines, etc) and causes.

Glue spraying involves exposure to solvents and other components of the glue. Smoke from heated glue may contain irritants derived from the PURs - such as aldehydes, phenols, and nitrous oxides ${ }^{20}$ - as well as cyanides and flame retardants. Moreover, some workers in the present study were also exposed to other agents-for example, colophony in melting glue, ${ }^{2}$ and dusts. ${ }^{21}$ These factors might, although only to some extent, confound the exposure-response relations.

In accordance with earlier findings from the same factory, ${ }^{10}$ and other studies of isocyanates, ${ }^{2-6}$ the associations between exposure, metabolites, and antibodies, on the one hand, and work related symptoms, on the other, were not confounded, or modified, by smoking or atopy. However, a history of atopy seemed to select workers to jobs without exposure, as atopic workers had both lower P-MDX and S-IgG-MDI.

The exposure categories were not homogenous for working methods, and intensity and duration of exposed work. One example is the four glue sprayers who used the gluing machine; their exposure to glue was unlike that of other sprayers. Also, some workers had recently changed work tasks.

Associations between metabolites or protein adducts in plasma or urine on the one hand, and exposure to monomer isocyanates, on the other, have been repeatedly reported. ${ }^{152-26}$ However, the value of such biomarkers to define exposure to thermodegradation products of PUR is less well known. ${ }^{7-10}$ We found that heating was associated with P-MDX. Heat guns generate high temperature. Interestingly, users of these had higher P-MDX and P-2,4-TDX than other heaters. Glue spraying was associated with P-TDXs. A probable explanation is that the sprayers often also used heat guns, and that the heat decomposed the TDI flexible foam. In support of this possibility, no P-TDX was found in glue sprayers, who did not also heat.

P-MDX was acceptable as a biomarker of exposure (table 6). However, our present results are not optimal for such an evaluation, as no totally unexposed subjects were included. Further, differences in metabolism between people may explain part of the variation. ${ }^{82728}$
U-MDX and U-TDX correlated with the corresponding plasma metabolites, but not highly. The complex and intermittent exposures combined with the multiple component elimination kinetics may have obscured the picture. ${ }^{9}$

Metabolites in body fluids, reflecting systemic absorption, may not be the best markers of exposure when the concern is local symptoms of the eyes and airways. Further, measurement of metabolites at a single occasion does not define the long term exposure, as the biological half lives of P-MDX, ${ }^{79}$ and P-TDX, ${ }^{9}{ }^{29}$ are as short as about 2-3 weeks, U-MDX and U-TDX with two elimination phases days (to weeks), ${ }^{7} 929$ and U-HDX probably hours. ${ }^{15} 27$ This limits the ability to detect associations with effects. On the other hand, for specific IgE and IgG, the biological half lives are much longer, ${ }^{30-33}$ favouring identification of such relations.

We found U-TDXs in a few clerks and specific IgG against MDI, HDI, or TDI in almost the same fractions of clerks and workers. The reason is probably that clerks were also slightly exposed. Thus, among the six clerks positive in at least one of the specific antibodies, two had earlier been workers, two visited the factory every day, and two had their office rooms close to the production. Also, the smell of organic solvents indicated air movements from the factory to the office.

There may be some cross reactivity between (IgG or IgE) specific antibodies, ${ }^{30} 3234$ but the present associations with exposures and effects support some specificity.

A qualitative association between specific antibodies and exposure to isocyanates has been well known for decades, ${ }^{2-6} 32$ but data on quantitative relations have been scarce. In the present study, there were some correlations between IgG antibodies and relevant metabolites. When used as a biomarker of current exposure, S-IgG-MDI has a low sensitivity, but high specificity (table 6). Exposure in earlier

Table 6 Sensitivity and specificity (\%) of classification of exposure to sprayed or heated glue for work related symptoms of the airways, and of metabolites of 4,4'-diphenylmethane diisocyanate (MDI; P-MDX) in plasma and specific IgG against MDI for exposure and work related symptoms of the airways (S-IgG-MDI) in 152 workers and 14 clerks, potentially exposed to sprayed or heated polyurethane glue

\begin{tabular}{lll}
\hline & Exposure & Airways \\
\hline Exposure: & & \\
Sensitivity & - & 68 \\
Specificity & - & 57 \\
P-MDX: & & \\
LM: & 85 & 78 \\
Sensitivity & 64 & 46 \\
Specificity & & \\
Mediant: & 73 & 60 \\
Sensitivity & 75 & \\
Specificity & & \\
S-IgG-MDI: & & 67 \\
Mediant: & 54 & 61 \\
Sensitivity & 61 & 49 \\
Specificity & & 73 \\
Positive & & \\
Sensitivity & 46 & \\
Specificity & 81 &
\end{tabular}

${ }^{\star} \mathrm{LM}=$ limit of measurement; the estimation of sensitivity and specificity refers to values above this limit.

†The estimation refers to values above the median.

$\ddagger$ The estimation refers to positive S-IgG-MDI values. 
work tasks and differences in immunogenetics between people may explain part of the variation.

There was a notable background prevalence of work related symptoms in the no spray no heat group- $21 \%$ of women and $18 \%$ of men-possibly due to intermittent exposure to isocyanates in combination with dusts ${ }^{21}$ and solvents. ${ }^{37}$ Interestingly, in the air measurements from 1993, relatively high concentrations of MDI (up to $7.1 \mu \mathrm{g} / \mathrm{l}$ ) were found in the no spray no heat group, indicating a widespread contamination of the workplace. ${ }^{10}{ }^{12}$

Spraying of PUR glue on the one hand, and work related symptoms and decreased lung function on the other, were associated. This agrees with earlier knowledge. ${ }^{2-4}$ Workers who heated glues (except maybe for gun heaters) had no increase of work related symptoms. However, in other settings, heating of PUR generated work related symptoms. ${ }^{1}{ }^{6} 213438-41$ Surprisingly, the workers who heated glues also had better lung function than the others; this might be due to selection. The fact that long term employees had better lung function, and fewer work related symptoms than short term employees indicates the possibility of a healthy worker selection. It should also be noted that the spirometric differences between gluers and non-gluers, and between heaters and nonheaters, were slight and of doubtful clinical significance.

Exposure to isocyanates has traditionally been associated with occupational asthma, occasionally also with allergic alveolitis. ${ }^{24}$ In the present study, the 17 workers with work related symptoms of the lower airways had slightly better lung function than other workers; none of the subgroups (dyspnoea and cough) had any decrease in lung function. The symptoms of the lower airways were of a transient nature, and the mechanism behind them unknown. Interestingly, $11(65 \%)$ of the workers with symptoms of the lower airways versus $20(15 \%)$ of the others reported a history of non-specific bronchial hyperresponsiveness $(\mathrm{p}<0.0001, F)$. Also, 14 of them underwent metacholine testing within a year of the present investigation; seven (50\%) showed varying degrees of hyperresponsiveness (Littorin et al, unpublished data).

Nose symptoms were common, as has occasionally been noted in other studies. ${ }^{5}{ }^{16}$ Interestingly, in nasal lavage samples from some of the workers, we could detect MDX and TDX (Littorin et al, unpublished data). On the other hand, eye symptoms seemed not to be associated with the exposure.

The effects associated with isocyanates in this study were probably even greater than hitherto presented. Thus, within the past 3 to 6 months, 12 workers reported infrequent airways symptoms, nine recurrent face flush and rash, two work related fevers, and others throat irritation. ${ }^{5}$ In summary, 74 workers (49\%) had various strictly work related symptoms. ${ }^{12}$

There were increased risks of work related symptoms of the airways in workers with high metabolites related to MDI and TDI, as described earlier. ${ }^{10}$ Thus, the metabolites may be used as biomarkers of risk. The sensitivity of P-MDX was fairly good, the specificity lower (table 6).

As has often been reported for cases of asthma related to isocyanates, ${ }^{2-6} 333536$ we found, in general, that the present symptoms were not associated with positive specific IgE. However, S-IgG-MDI, as well as total IgG and IgM, were associated with work related symptoms. The sensitivity of S-IgG-MDI as a biomarker of risk was moderate, the specificity better (table 6). However, the significance of specific IgG for respiratory disease is still questionable. ${ }^{461642}$ Thus, it is of interest that the work related symptoms of the lower airways subgroup with cough, but not the subgroup with dyspnoea etc, had both high metabolites and IgG antibodies. Possibly, the symptoms in the two subgroups may reflect different disorders or disease mechanisms. ${ }^{2-6} 43$

Remarkably, the worker who had the highest S-IgG-MDI value (as well as S-IgG-TDI and S-IgG-HDI), had a history of attacks of severe exposure related fevers 6 years earlier (reported to the Labour Inspectorate at that time). She was now only slightly exposed and had only discrete mucous membrane irritations and no work related symptoms.

Not all workers with high concentrations of biomarkers reported work related symptoms. There are several possible explanations: the symptomatic workers may be the most susceptible ones for genetic or acquired metabolic ${ }^{827} 28$ or immunological ${ }^{44}$ reasons, or they may be prone to hyperreactivity.

Moreover, workers with work related symptoms were often transferred to less exposed work tasks, which probably obscured the exposure-response relations. Also, the cross sectional approach brought about a healthy worker selection, which caused underestimates of the effects. Thus, out of the 27 workers on long term sick leave, $89 \%$ had had work related symptoms and $70 \%$ were sick listed because of these. Seventy four per cent of the sick listed workers had metabolites in blood or urine and $18 \%$ were positive for at least one of the isocyanate antibodies (Littorin et al, unpublished data).

Our data on metabolites and risks hardly offer a basis for proposing biological exposure limits for isocyanates; such limits related to the corresponding TLVs in air were recently suggested for $\mathrm{HDI}^{26}$ and $\mathrm{MDI}{ }^{45}$

The present risk found was unacceptable. Use of simple respirators and gloves seemed to have no effect on the prevalences of metabolites, antibodies, or symptoms. Thus, better preventive measures are needed.

This study was supported by funding from the AGS Fund, the VÅRDAL Foundation, the Medical Faculty, Lund University, the Malmohus County Council, and the European Union. Excellent technical assistance was given by $\mathrm{Mr}$ Mikael Adamsson, Ms Pia Apréa, Ms Birgitta Björk, Ms Monica Hansi, Mr Zoli Mikoczy, Ms Anita Nilsson, and Ms Gunnel Nilsson.

1 Fuchs S, Valade P. Étude clinique et expérimentale sur quelques cas d'intoxication par le Desmodur T (diisocyanate de toluylene $1-2-4$ et 1-2-6). Arch Mal Prof 1951;12:191-6.

2 Hagmar L, Nielsen J, Skerfving S. Clinical features and epidemiology of occupational obstructive disease caused by 
small molecular weight organic chemicals. Monogr Allergy 1987;21:42-58

3 Butcher BT, Mapp CE, Fabbri LM. Polyisocyanates and their prepolymers. In: Bernstein IL, Chan-Yeung M, Malo $\mathrm{J}-\mathrm{L}$, et al, eds. Asthma in the work-place. New York: Marcel Dekker, 1993:415-37.

4 Vandenplas O, Malo J-L, Saetta M, et al . Occupational asthma and extrinsic alveolitis due to isocyanates: current status and perspectives. Br F Ind Med 1993;50:213-28.

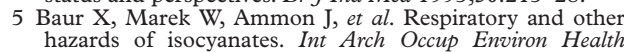
1994;66:141-52.

6 Bernstein JA. Overview of diisocyanate occupational asthma. Toxicology 1996;111:181-9.

7 Skarping G, Dalene M, Littorin M. 4,4'-methylenedianiline in hydrolysed serum and urine from a worker exposed to thermal degradation products of methylene diphenyl diisocyanate elastomers. Int Arch Occup Environ Health 1995;67: cyanate $73-7$.

8 Dalene M, Jakobsson K, Rannug A, et al. MDA in plasma as a biomarker of exposure to pyrolysed MDI based polyurethane: correlations with estimated cumulative dose
and genotype for $\mathrm{N}$-acetylation. Int Arch Occup Environ and genotype for $\mathrm{N}-\mathrm{a}$

9 Dalene M, Skarping G, Lind P. Workers exposed to thermal degradation products of TDI- and MDI based polyurethane: biomonitoring of 2,4-TDA, 2,6-TDA, and 4,4'-MDA in hydrolysed urine and plasma. Am Ind Hyg Assoc f 1997;58:587-91.

10 Skarping G, Dalene M, Svensson B-G, et al. Biomarkers of exposure, antibodies, and respiratory symptoms in workers heating polyurethane glue. Occup Environ Med 1996;53: 180-7.

11 Tinnerberg H, Spanne M, Dalene M, et al. Determination of complex mixtures of airborne isocyanates and amines. of complex mixtures of airborne isocyanates and amines. Part 3. Methylediphen structural analogues after thermal degradation of polystructural analogues after thermal

12 White WG, Sugden E, Morris MJ, et al. Isocyanate-induced asthma in a car factory. Lancet 1980;i:756-60.

13 Nielsen J, Welinder H, Schütz A, et al. Specific serum antibodies against phthalic anhydride in occupationally exposed subjects. $\mathcal{F}$ Allergy Clin Immunol 1988;82:126-33.

14 American Thoracic Society. Standardization of spirometry: 1987 update. Am Rev Respir Dis 1987;136:1285-98.

15 Tinnerberg H, Skarping G, Dalene M, et al. Test chamber exposure of humans to 1,6- hexamethylene diisocyanate and isophorone diisocyanate. Int Arch Occup Environ Health 1995;67:367-74.

16 Welinder $\mathrm{H}$, Nielsen J, Bensryd I, et al. IgG antibodies against polyisocyanates in car painters. Clin Allergy 1988;18:85-93.

17 Hosmer DW, Lemeshow S. Applied logistic regression. New York: John Wiley, 1989

18 Altman DG. Practical statistics for medical research. London: Chapman and Hall, 1991.

19 Lind P, Skarping G, Dalene M. Biomarkers of toluene diisocyanate and thermal degradation products of polyurethane, with special reference to the sample preparation. Analytica with special reference to the sam
Chimica Acta 1996;333:277-83.

20 Renman L, Sangö C, Skarping G. Determination of isocyanate and aromatic amine emissions from thermally degraded polyurethanes in foundries. Am Ind Hyg Assoc $\mathcal{F}$ 1986;47:621-8

21 Woellner RC, Hall S, Greaves I, et al. Epidemic of asthma in a wood products plant using methylene diphenyl diisocyanate. Am ₹ Ind Med 1997;31:56-63.

22 Rosenberg C, Savolainen H. Determination of occupational exposure to toluene diisocyanate by biological monitoring. f Chromatogr 1986;367;385-92.

23 Maître A, Bérode M, Perdrix A, et al. Biological monitoring of occupational exposure to toluene diisocyanate. Int Arch Occup Environ Health 1993;65:97-100.

24 Schütze D, Sepai O, Lewalter J, et al. Biomonitoring of workers exposed to $4,4^{\prime}-$ methylenedianiline or 4,4' workers exposed to $4,4-$ methylenedianiline or $4,4-1$ 573-82.
25 Sepai O, Henschler D, Sabbioni G. Albumin adducts, hemoglobin adducts and urinary metabolites in workers exposed to 4,4'-methylenediphenyl diisocyanate. Carcinogenesis 1995;16:2583-7.

26 Maître A, Bérode M, Perdrix A, et al. Urinary hexane diamine as an indicator of occupational exposure to hexamethylene diisocyanate. Int Arch Occup Environ Health 1996;69:65-8.

27 Brorson T, Skarping G, Nielsen J. Biological monitoring of isocyanates and related amines. II. Test chamber exposure of humans to 1,6-hexamethylene diisocyanate (HDI). Int Arch Occup Environ Health 1990;62:385-9.

28 Bérode M. Detoxification of an aliphatic amine by N-acetylation: experimental and clinical studies. Biochem Int 1991;24:947-50.

29 Lind P, Dalene M, Tinnerberg H, et al. Biomarkers in hydrolysed urine, plasma and erythrocytes among workers exposed to thermal degradation products from toluene diisocyanate foam. Analyst 1997;122:51-6.

30 Malo J-L, Ouimet G, Cartier A, et al. Combined alveolitis and asthma due to hexamethylene diisocyanate (HDI), with demonstration of crossed respiratory and immunologic reactivities to diphenylmethane diisocyanate (MDI). $\mathcal{F}$ Allergy Clin Immunol 1983;72:413-9.

31 Karol MH, Jin R, Rubanoff B. Clinical and experimental evaluation of isocyanate lung injury. Comments on Toxicology 1989;3:117-30

32 Littorin $\mathrm{M}$, Truedsson $\mathrm{L}$, Welinder $\mathrm{H}$, et al. Acute respiratory disorder, rhinoconjunctivitis, and fever associated with pyrolysis of polyurethane derived from MDI. Scand $\mathcal{F}$ Work Environ Health 1994;20:216-22.

33 Tee RD, Cullinan P, Welch J, et al. Specific IgE to isocyanates: a useful diagnostic role in occupational asthma. F Allergy Clin Immunol 1998;101:709-15.

34 Tse KS, Johnson A, Chan H, et al. A study of serum antibody activity in workers with occupational exposure to diphenylmethane diisocyanate. Allergy 1985;40:314-20.

35 Keskinen H, Tupasela O, Tiikkainen U, et al. Experiences of specific IgE in asthma due to diisocyanates. Clin Allergy 1988;18:597-604

36 Wass U, Belin L. Immunologic specificity of isocyanateinduced IgE antibodies in serum from 10 sensitized workers. F Allergy Clin Immunol 1989;83:126-35.

37 Akbar-Khanzadeh F, Rivas RD. Exposure to isocyanates and organic solvents, and pulmonary-function changes in workers in a polyurethane molding process. $f$ Occup Environ Med 1996;38:1205-12.

38 Tanser AR, Bourke MP, Blandford AG. Isocyanate asthma: respiratory symptoms caused by diphenyl-methane diisocyanate. Thorax 1973;28:596-600.

39 Zammit-Tabona M, Sherkin M, Kijek K, et al. Asthma caused by diphenylmethane diisocyanate in foundry workers: clinical, bronchial provocation, and immunologic studies. Am Rev Respir Dis 1983;128:226-30.

40 Liss GM, Bernstein DI, Moller DR, et al. Pulmonary and immunologic evaluation of foundry workers exposed to methylene diphenyldiisocyanate (MDI). I Allergy Clin Immunol 1988;82:55-61.

41 Jakobsson K, Kronholm-Diab K, Rylander L, et al. Airway symptoms and lung function in pipelayers exposed to thermal degradation products from MDI-based polyurethane. Occup Environ Med 1997;54:873-9.

42 Cartier A, Grammer L, Malo J-L, et al. Specific serum antibodies against isocyanates: association with occupational asthma. $\mathcal{F}$ Allergy Clin Immunol 1989;84:507-14.

43 Raulf-Heimsoth M, Baur X. Pathomechanisms and pathophysiology of isocyanate-induced diseases: summary of present knowledge. Am f Ind Med 1998;34:137-43.

44 Bignon JS, Aron Y, Ju LY, et al. HLA class II alleles in isocyanate-induced asthma. Am $\mathrm{f}$ Respir Crit Care Med 1994;149:71-5.

45 Deutsche Forschungsgemeinschaft. List of $M A K$ and BAT values 1998. Report number 34 of the commission for the investigation of health hazards of chemical compounds in the work tigation of health hazards of chemical com 